\title{
Anticoagulant Capacities of Some Medicinal Mushrooms
}

\author{
Waill A. Elkhateeb ${ }^{1 *}$, Ghoson M. Daba ${ }^{1}$, Marwa O. Elnahas ${ }^{1}$, Paul W. Thomas ${ }^{2,3}$ \\ ${ }^{1}$ Chemistry of Natural and Microbial Products Department, Pharmaceutical Industries Researches Division, \\ National Research Centre, El Buhouth St., Dokki, 12311, Giza, Egypt. \\ ${ }^{2}$ Mycorrhizal Systems Ltd, Lancashire, PR25 2SD, UK. \\ ${ }^{3}$ University of Stirling, Stirling, FK9 4LA, UK
}

*Corresponding Author: Waill A. Elkhateeb, Chemistry of Natural and Microbial Products Department, Pharmaceutical Industries Researches Division, National Research Centre, El Buhouth St., Dokki, Giza, Egypt.

\begin{abstract}
Studies with mushrooms have been developed recently and it is figured out that potent properties of secondary metabolites from different mushroom species show great biological activities. There is a growing interest in active metabolites that are obtained from natural sources as an alternative to synthetic drugs. In the review, the potential use of mushroom extract as an anticoagulant agent has been discussed.Hydnellum peckii, Ganoderma lucidum,Geastrum fimbriatum and Auricularia auricula-judaeextracts exhibited a promising anticoagulantactivity.
\end{abstract}

Keywords: Medicinal Mushrooms, Anticoagulant,Hydnellum peckii, Ganoderma lucidum,Geastrum fimbriatum, Auricularia auricula-judae..

\section{INTRODUCTION}

Health problems related to heart, blood vessels, and thrombosis (Thromboembolic condition) including ischemic stroke, acute myocardial infarction, unstable angina, pulmonary embolism, and deep vein thrombosis are of the major causes of death in the World [1,2]. Blood coagulation plays serious roles in the incidences of cardiovascular problems. Achieving balance in human body between thrombus formation and destruction of it is very critical. Thanks to a system including platelets, the vascular endothelium, the coagulation cascade, and the fibrinolytic system [3-5]. This complexity in accomplishing the equilibrium in this system made it challenging to be controlled using drugs, and there is always high risk of bleeding due to the narrow therapeutic index of some drugs. This inconvenience prompted researchers to screen for new safe anticoagulants that do not require this strict monitoring.Examples for famous anticoagulant drugs are vitamin $\mathrm{K}$ antagonists, such as warfarin; novel anticoagulants (NACs) such as direct thrombin inhibitors (as dabigatran), and factor $\mathrm{Xa}$ inhibitors (as rivaroxaban, apixaban) [6].

Mushrooms are tremendous sources forvariouscompounds of therapeutic capacities [7].Humans knew this from millennia, and hence consumed mushroom all over the world due to their high nutritional values, and some medicinal properties.

A wide variety of compounds isolated from many species of mushrooms, have been identified [8], most of them were fatty acids, terpenoids, proteins, phenols, lectins, steroids, and polysaccharides [9-11].

Mushrooms have been reported to exhibit an assortment of biological activities including but not limited to anticancer, antimicrobial, hypocholesterolemic, antioxidant, antihypertensive, antidiabetic, anti-obesity, hepato-protective, antiaging, anti-allergic, and anti-coagulant activities [7,11].

In this review, the anticoagulant capacities of some mushrooms has been discussed. Out of the thousands of mushroom species already identified, some species were reported as promising sources of anticoagulant compounds. Examples are Hydnellum peckii (bleeding tooth mushroom); Auricularia auricula-judae (Jelly ear mushroom); Geastrum fimbriatum (Earthstar mushroom); and the famous Ganoderma lucidium (Lingzhi or Reishi). 


\section{Hydnellum PECKII (BLeEding TOOTH FunguS)}

Hydnellum peckii belong to the Aphyllophorales order and the Hydnaceae family, commonly called the bleeding tooth fungus. They are widely dispersed in Europe and the Pacific Northwest, commonly in association with conifers and can be found among moss and pine litter. They fruit in the summer months as a solitary or fused fruiting bodies. These fungi are mycorrhiza, living in symbiosis with vascular plant roots. H. peckii are non-toxic. H.peckii have $2-5 \mathrm{~mm}$ spines, similar to teeth, on the underside of their cap. As these fungi mature, they become less descript becoming turning grey or brown in color.However, their taste has been described as bitter pepper deeming it inedible. Nitrogen deposition resulting from atmospheric pollution is believed to be a key factor in the observed decline of H. peckii populations, particularly in areas of Europe [12].

\section{Hydnellum PECKII Natural Products}

This fungus does have several beneficial uses. The mushroom of $H$. peckii contains atromentin, which has antibacterial and anticoagulant properties. Additionally, the oozing red "blood" can be used to dye fabrics. [12,13].

\section{Medicinal EfFects of HydNELLUM PeCKIIAS AntiCoAgulant ACTIVITY}

Screening of a $70 \%$ ethanolic extract of Hydnellum peckii revealed the presence of an effective anticoagulant, named atromentin, similar in activity to the well-known anticoagulant heparin. In vivo, $1 \mathrm{mg}$ of the ethanol extract was equivalent to 0.58 units of heparin. In vitro, $1 \mathrm{mg}$ of purified atromentin was equivalent to 5.1 units of heparin and $2.3 \mathrm{mg}$ of $70 \%$ ethanol extract [14].

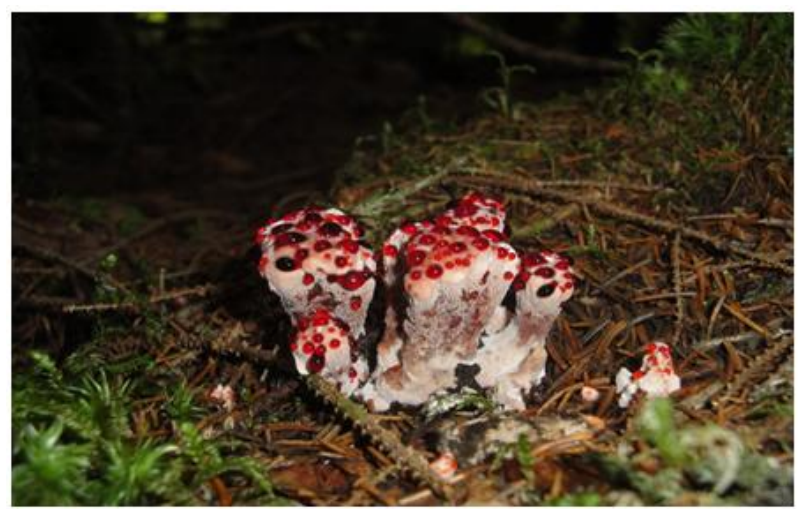

Fig1. Hydnellum peckii(Photographs taken by dnsolie, Locality United States, Alaska, Southeast Fairbanks County, hosted by http://mycoportal.org).

\section{AURICUlaria AURICULA-JUdAE (JELly EAR Fungus)}

Auricularia auricula-judae or as commonly known Judas's ear or the jelly ear fungus, is an edible mushroom characterized by its brownish, ear-like jelly shape. The fruit bodies of Auricularia auricula-judae grow on wood and have been commonly used as a food and as antidiabetic, antihypertensive, antiinflammatory, immunomodulatory, anticancer, and antimicrobial medications in many Asian countries. Its fruit body is characterized by its high contents of carbohydrates, protein, and minerals such as calcium, phosphorous, potassium, and iron [15,16].Most Auricularia species are edible and are grown commercially in China. Auricularia auricula-judae is a popular ingredient in many Chinese dishes; it has been used as a blood tonic and has shown antitumor, hypoglycemic, anticoagulant, and cholesterol-lowering properties [17,18].Auricularia auricula-judae represents a promising source for novel chemical compounds of different biological functions, and there extracts were reported to have anticoagulant activity [19].

Auricularia is a key genus among edible macrofungi, sourced as either wild or cultivated mushrooms. Auricularia species are utilized as nutrient-rich foods and medicinal resources, with particular prominence in Traditional Asian Medicine.Auricularia species are used predominantly within the food industry, there is strong potential for their use in the production of therapeutic drugs, thus making it necessary to identify relevant bioactive compounds and further our understanding of its pharmacological properties [20].

\section{Auricularia Auricula-Judae natural Products}

Carbohydrates are the major nutritional constituent of edible Auricularia species in addition to proteins, fat, fiber, ashes vitamins and minerals. Also polysaccharides were the major active compounds found in edible Auricularia species in relation to their nutritional value, extraction 
methods, and pharmacological properties. Potential medical applications for these compounds include the production of novel therapeutic drugs for treating diseases such as cancer, diabetes, and cardiovascular disorders [20].

Elkhateeb et al., [19] reported that in Auricularia auricula-judaen-hexane extract, seventeen compounds were identified. Tetradecane (1.1\%), Pentadecane $(1.5 \%)$, Hexadecane $(0.8 \%)$ as hydrocarbon compounds. Hexadecanoic acid, methyl ester (2.25\%), cis- 9-hexadecenoic acid (0.8\%), hexadecanoic acid (5.7\%), 1-(5'-acetoxy-2',4'-dimethoxy-6'-hydroxyphenyl)-2-methylanthraquinone (1.35\%), 9,12- octadecadienoic acid (z,z)-, methyl ester (2.63\%), 9-octadecenoic acid (Z)-, methyl ester (7.05\%), 11-octadecenoic acid, methyl ester (1.47\%), octadecanoic acid, methyl ester $(1.22 \%)$. It was found that oleic acid (62.31\%) was epresented as the major compound, 6,9,12-octadecatrienoic acid, methyl ester (1.05\%), mesoaminoacactaethylporph (1.65\%), 2-(2,6-dimethoxy-4-(2,2-bis (ethoxycarbonyl) ethyl]phenyl)-9-(2,6- dimethoxyphenyl)-1,10-phenanthroline (0.89\%), 1,2benzenedicarboxylic acid, bis (2-ethylhexyl) ester (5.20\%) and anthraergosta-5,7,9,22-tetren-3-ol $(1.36 \%)$.

Kadnikova et al., [21]reported that main components of Auricularia auricula-judae (ash, protein, fat, total carbohydrate), water-soluble polysaccharide, cellulose, chitin, pectin, uronic acids, amino acid and mineral element contents, as well as neutral sugar composition were determined. This fungus contains $3.6 \%$ of ash, $12.5 \%$ of protein, $1.7 \%$ of fat and a large amount of carbohydrates $(66.1 \%)$ per dry matter.

\section{Medicinal EFFECTS OF AURICUlaria AURICUla-JUdAEAS ANTICOAGUlant ACTIVITY}

An acidic polysaccharide with anticoagulant activity was isolated from the edible mushroom Auricularia auricula using water, alkali or acid extracts. The alkali extract showed the highest anticoagulant activity and was thereby further purified using gel filtration chromatography. Specific anticoagulant activity of the purified polysaccharide was $2 \mathrm{IU} / \mathrm{mg}$ and its average mass was $\mathrm{f} 160$ $\mathrm{kDa}$. The polysaccharide from Auricularia auricula contains mainly mannose, glucose, glucuronic acid and xylose but no sulfate esters [15].

Auricularia auricula anticoagulant activity was due to catalysis of thrombin inhibition by antithrombin but not by heparin cofactor II. Inhibition of Factor Xa by antithrombin was not catalyzed by the polysaccharide. The glucuronic acid residues were essential for the anticoagulant action of the mushroom polysaccharide since the activity disappeared after reduction of its carboxyl groups. The polysaccharides from these mushrooms may constitute a new source of compounds with action on coagulation, platelet aggregation and, perhaps, on thrombosis [15].

Therefore the edible mushroom Auricularia auricula may become a new source of anticoagulant compounds. Evaluation of Auricularia auricula polysaccharide as a novel alternative agent in thrombosis therapy requires further studies on characterization of its anticoagulant nature and the possible effect on experimental models of thrombosis [15].
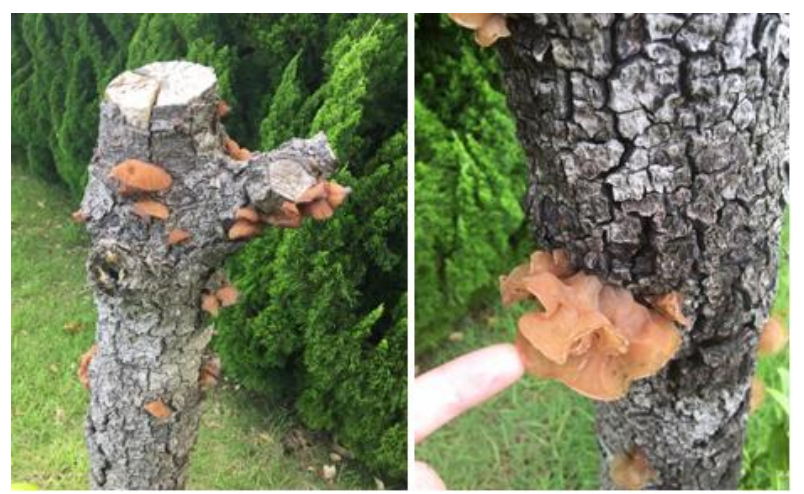

Fig2. Auricularia auricula-judae(Photographs taken by Waill A. Elkhateeb, Locality:Hakozaki Higashi-ku Fukuoka-shi Japan).

\section{GEASTRUM Fimbriatum (EARThSTAR FUnGUS)}

Geastrum fimbriatum is an inedible mushroom belonging to family Geastraceae. It is also named fringed earthstar or sessile earthstar. It gains its name from its morphology. The word fimbriatum means fringed or fibrous referring to the fringed opening of the spore sac [22]. 
In early stages, it lies in soil like a stone where it is rounded in shape, and when it gets mature it pushed up to the soil surface and its outer peridium splits into several segments or rays (ranging between 5 to 8 segments). These rays are curved downwards exposing the inner peridium (spore sack)

[23]. The outer peridium then start to expand to the outside developing a star-like shape on the ground. Before being expanded these segments outer surfaces are cottony with some soil particles adhered to them, while after expansion these cottony surfaces peel off revealing a grayish brown, smooth surface. The spore sack is about $2 \mathrm{~cm}$ in diameter with conical apical pore and buffy to greyish brown smooth surface. The spores are light brown in color with globous surface and range between 4-7 $\mu \mathrm{m}$, the powdery spores eject from the sac when it is hit by raindrops or blown by a wind. It has a large fruit bodies (up to $5 \mathrm{~cm}$ across) with no distinguishing odor or taste. Although it was mentioned that Geastrum fimbriatum is an inedible mushroom [22], it was found to be eaten by Madhya Pradesh tribe [23].

\section{DiSTRIBUTION AND ECOLOGY}

Geastrum fimbriatum is a saprobic, hypogeous mushroom that has been reported in broad leaved wood and conifers, they may be single or aggregated in small groups. It is found in several locations including Europe [24], Latin America [25], eastern North America [26] and Asia [27].

\section{Geastrum Fimbriatum natural Products ANd their Anticoagulant ACTivity}

As it was mentioned before, the blood vessels health problems and thrombosis are considered one of the major reasons leading to death in the World [1]. Due to the restriction to the use of many anticoagulants that show undesirable side effects including hemorrhagic risk, much more interest has been directed towards developing new safer, potent and specific antithrombotic as well as anticoagulant agents that exhibit less risk and are compatible with other drugs [28].Warfarin is an example of anticoagulant drug that exhibits many undesirable side effects including gum and nasal bleeding, bruising, haemoptysis, dark or bloody vomit or stool as well as many other complications [28]. There could be other better choices that prevent and treat a variety of cardiovascular diseases and that could be obtained from nature with lower toxicity and no side effects $[\mathbf{2 9 , 3 0}]$.

The studies showed that Geastrum fimbriatum demonstrated a promising anticoagulant activity, where the activated partial thromboplastin time (APTT) assay which is used to estimate the intrinsic coagulation pathway showed that Geastrum fimbriatum ethanolicextract prolonged the coagulation time (67 seconds) compared to DMSO which is the negative control (50 seconds), however the prothrombin time (PT) which was employed for the evaluation of the extrinsic coagulation pathway did not show any positive activity. Both assays were conducted using commercial human plasma, where acetylsalicylic acid was used as a positive control and dimethyl sulphoxide (DMSO) used as a negative control[29,30].

These results revealed that Geastrum fimbriatum can find potential applications as new anticoagulant as well as antiinflammatory agent from natural source. However, further studies should be conducted to evaluate the safety and the cytotoxicity of that mushroom.

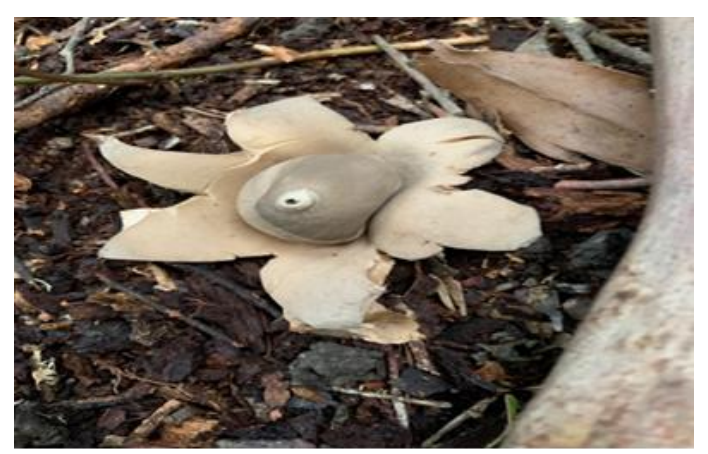

Fig3. Geastrum fimbriatum (Earthstar fungus) (collected by MBouck, Locality: Australia, Victoria, East Warburton, hosted by http://mycoportal.org).

\section{Ganoderma Luciduma Polyporus Mushroom}

Ganoderma lucidum is a polypore mushroom belonging genus Ganoderma that grows as saprotrophs or parasites [31]. It has been used for many years in Far East countries including China, Japan, and 
Korea, as a potent medicinal fungus [32]. It is known by two different names in China and Japan, the Chinese call it "lingzhi" referring to its essence of immortality and spiritual potency, while the Japanese named this mushroom reishi or mannentake which means 10,000 year mushroom [32].

In Latin, the word lucidus means brilliant or shiny referring to the mushroom's fruiting body appearance which is varnished and sculptured [33]. It is a dark large mushroom with a woody texture and glossy external surface, it has a kidney shaped cap giving it a distinct morphology [31].It is not classified as edible mushrooms, due to their bitter taste also their fruiting bodies are so hard with no fleshy texture making it so hard to be eaten [34]. G. lucidum exhibits a great popularity for its pharmaceutical benefits rather than the nutritional ones[33].

\section{DiSTRIBUTION AND ECOLOGY}

Ganoderma lucidum is an annual mushroom that prefer hot and humid climates in the subtropical regions of the Orient [33]. It can grow as saprotrophs or parasites [31] on adiverse range of trees, especially deciduous giant trees such as maple, oak, willow, elm.It grows close to the soil surface at the stump of such trees and sometimes it appears on the soil surface as it arises from buried roots [35]. On the other hand, it is less frequently growing on coniferous trees found in Asia, Europe and America.

The wild lingzhi is very rare since out of each 10,000 deciduous trees only two or three show lingzhi growth. Nevertheless, lingzhi can be artificially cultivated now a day on various substrates including sawdust/woodchips or hardwood logs [36], residues of farm crops or cotton seed husk [37], sunflower seed hull [38], wheat straw [39], corn cobs [40].

Ganoderma species are white rot fungi that show a critical ecological role in nutrient mobilization due to their decomposing effect towards woody plants. They are also effectual for bioremediation and bioenergy production due to their lignocellulose decomposing enzymes [41,42].

\section{Ganoderma Lucidumnatural Products}

It is well established that about $90 \%$ of the mushrooms weight is water and the remaining $10 \%$ is formed of other components such as protein, carbohydrates, vitamins and minerals, ash and fiber. It was reported that the nonvolatile components of G. lucidum consists of 7-8\% crude protein, 26-28\% carbohydrate, $1.8 \%$ ash, , $59 \%$ fiber, and $3-5 \%$ fat [43].

Polysaccharides, triterpenes and peptidoglycans are considered the major biologically active compounds in G. lucidum $[\mathbf{4 4 , 4 5}]$. However, their amounts can be extremely diverse in natural and commercial products, this diversity results from using different species as well as the variation in the production conditions [33].

A variety of polysaccharides that differs in their sugar and peptide compositions as well as differ in their molecular weight (e.g., ganoderans A, B, and C) have been obtained from G. lucidum spores, mycelia and fruit bodies. Due to the unique chemical and rheological structure of these polysaccharides, they show a wide range of crucial biological activities such as antitumor, antiinflammatory, immunostimulating and hypoglycemic effects [46-48]. The structural analysis of the produced polysaccharides revealed that the major sugar in their structures is the glucose [33].

Among the other important bioactive compounds isolated from G. lucidum arepeptidoglycans. These include a proteoglycan that shows a promising antiviral activity,also a fucose-containing glycoprotein fraction was also extracted from G. lucidum [49], additionally, another watersoluble glycopeptide was extracted from the fruit bodies [50].

Terpenes are alsovital bioactive compounds produced by G. lucidum, which are well known to exhibitcrucialpharmacological activities including antitumorigenic, hypolipidemic and antiinflammatory activities [51]. These natural compounds have carbon skeletons formed of one or more isoprene $\mathrm{C}_{5}$ units, their molecular weights range from 400 to $600 \mathrm{kDa}$ and they are extremely oxidized with complex chemical structure [51]. The Extraction of triterpenes is carried out by using solvents such as methanol, ethanol, chloroform, ether, and acetone. This step is followed by a purification process usually by using normal and reverse phase HPLC [52]. 
Kubota et al. [53] reported the first triterpenes extracted from G. lucidum which are the ganoderic acids $\mathrm{A}$ and B. After that, hundred or more triterpenes were isolated from G. lucidum. The chemical composition of these triterpenes were well identified and it was observed that the majority of the triterpenes are ganoderic and lucidenic acids, while other triterpenes including ganoderiols, ganoderals and ganodermic acids also have been reported [54].

Beside these major compounds, the elemental analysis showed the presence of several vital minerals in G. lucidum fruit bodies. These include potassium, calcium and magnesium, phosphorus, sulfur, and silica were detected. Other minerals were also reported but they are found in smaller amounts such as iron, copper, manganese, strontium, sodium. Some heavysuch as mercury, lead and cadmium metals are detected in small amounts as well [55].

\section{Anticoagulant ACTIVITy}

Ganoderma lucidum has been used as traditional medicinal herb to treat various disease for about two thousand years [56]. It shows a great usefulness for the treatment of various cardiovascular disorders.Ganoderma lucidum produces metalloprotease that exhibits both antithrombotic and fibrinolytic activities [57]. The blood is clotting and lysis systems are highly regulated by several vital enzymes and any disturbance in these systems will results in life threating cardiovascular diseases. As it was known that blood clots are formed by thrombin from fibrinogen however they are lyzed by plasmin that is activated from plasminogen by tissue plasminogen activator. A fibrin plate methods assay was employed to test fibrinolytic protease of G. lucidum extract. A putative metalloprotease has been isolated from the mycelium of G. lucidum. The protease hydrolyzed human fibrin and fibrinogen as well as it showed a promising anticoagulant activity [57]. This enzyme was found to be a $\mathrm{Zn}^{2+}$ metalloprotease as each mol of protease contains about $1.07 \mathrm{~mol}$ of $\mathrm{Zn}^{2+}$. The purified enzyme was able to hydrolyze the $\alpha$, and $\beta$ chain when incubated with human fibrinogen, however it did not affect $\gamma$ chain of fibrinogen. On the other hand, thrombin, hemoglobin, immunoglobulin and albumin are not affected by the presence of the protease enzyme under similar conditions [57].

An anticoagulant activity using human plasma was also displayed by G. lucidum metalloprotease. The activated partial thromboplastin time (APTT) and thrombin time (TT) test in human plasma were used to evaluate the anticoagulant activity of the purified protease enzyme. As mentioned before APTT is employed to detect the coagulation defect in the intrinsic pathway, nevertheless TT assay is more sensitive to estimate the anticoagulant activity of the protease enzyme. The results showed that the prolonged TT could be related to the degradation of fibrin or fibrinogen. It was reported that the TT was prolonged by 2 and 3 times the control time at protease concentrations of 220 and $240 \mathrm{nM}$ respectively. However, the APTT required higher concentrations of the protease enzyme to reach 2 and 3 times the control value, where the protease concentrations were 1.1 and $2.2 \mu \mathrm{M}$ respectively [57].

Additionally, G. lucidum has a profound protective effect on the cardiovascular system since it is able to lower the blood cholesterol and triglyceride level as well as reduce the blood pressure. The clinical trials proved that two months administration of G. lucidum extract improved the blood pressure of hypertensive patients at the primary stage to reach normal blood pressure values [58]. Another study reported that G. lucidum extract prevented the development of atherosclerosis in rats as it lowered blood lipid level [59].

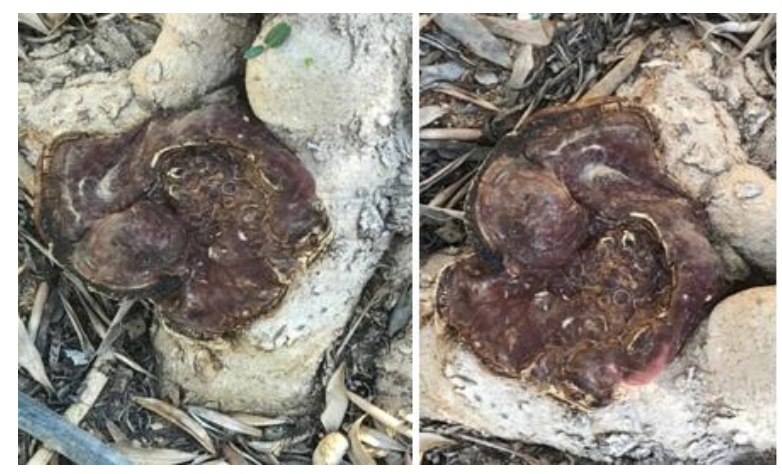

Fig4. Ganoderma lucidum(Photographs taken by Ahmed I. El-Diwany and Waill A. Elkhateeb, Locality: Cairo, Egypt).

Polysaccharides, one of the major bioactive compounds isolated from G. lucidum was found to improve many cardiovascular disorders such as chest pain and palpitation. Also it improves 
improvement in ECG in many cases, in addition to their hypotensive, antithrombotic and hypolipidemic activities [60].

As a conclusin, $G$. lucidum is regarded as a effective medicinal herb showing variable biological activities including control some cardiovascular diseaes which is a global leading cause of death. Furtherclinical trials should be conducted to evaluate and confirm the safety and efficacy of $G$. lucidum natural products .

\section{REFERENCES}

[1] Fares A. Winter cardiovascular diseases phenomenon. N. Am. Journal of Medical Science, 2013; 5: 266279

[2] Rakhi K, Bhama SK, Surya K, Anila KN, Lakshmi R. A Review on Noval Anticoagulants. International Journal of Pharmaceutical and Clinical Research 2017; 9(1): 96-99.

[3] Rickles F, and Falanga A. Molecular basis for the relationship between thrombosis and cancer. Thromb. Research, 2001; 102: 215-224.

[4] Dulay RM, De Guzman ML, Magisa RR, Mariano JC, San Pedro MC, Mangansat NJ,Peria JN. Philippine wild medicinal mushroom, Ganoderma lucidum (Curtis: Fr.) P. Karst., exhibits anticoagulative effect in intrinsic pathway. Advances in Environmental Biology, 2016; 10(4): 92-97.

[5] Alshareef HJ, Aloufi OF, Aljohani NJ, Mirdad OA, Alghamdi BA,Alqattan HA. Anticoagulants: Their Adverse Effects and Reversal. Egyptian Journal of Hospital Medicine, 2018; 70(6).

[6] Harter K, Levine M, Henderson SO. Anticoagulation drug therapy: a review. Western Journal of Emergency Medicine, 2015; 16(1), p.11-17.

[7] Biswas G, Nandi S, Kuila D, Acharya K. A comprehensive review on food and medicinal prospects of Astraeus hygrometricus. Pharmacognosy Journal, 2017; 9(6).

[8] Wasser SP. Medicinal mushrooms as a source of antitumor and immunomodulating polysaccharides. Applied Microbiology and Biotechnology, 2002; 60: 258-274.

[9] Moradali MF, Mostafavi H, Ghods S. and Hedjaroude GA. Immunomodulating and anticancer agents in the realm of macromycetes fungi (macrofungi). Int. Immunopharmacological, 2007; 101: 120-128.

[10] Liu DZ, Liang HJ, Chen CH, Su CH, Lee TH, Huang CT, Hou WC, Lin SY, Zhong WB, Lin PJ, Hung LF, Liang YC. Comparative anti-inflammatory characterization of wild fruiting body, liquid-state fermentation, and solid-state culture of Taiwan fungus camphoratus in microglia and the mechanism of its action. Journal of Ethnopharmacology, 2007; 113: 45-53.

[11] Elkhateeb WA, Daba GM, Thomas PW, Wen TC. Medicinal mushrooms as a new source of natural therapeutic bioactive compounds. Egyptian Pharmaceutical Journal, 2019; 18(2): 88-101.

[12] Holden L. Scotland's rare tooth fungi: an introduction to their identification, ecology, and management. Plant life International, 2008.

[13] Evenson VS. Mushrooms of Colorado and the Southern Rocky Mountains. Big Earth Publishing, 1997.

[14] Khanna JM, Malone MH, Euler KL, Brady LR. Atromentin Anticoagulant from Hydnellum diabolus. Journal of pharmaceutical sciences, 1965; 54(7): 1016-1020.

[15] Yoon SJ, Yu MA, Pyun YR, Hwang JK, Chu DC, Juneja LR, Mourao PA. Nontoxic mushroom Auricularia auricula contains a polysaccharide with anticoagulant activity mediated by antithrombin. Thrombosis Research, 2003; 112: 151-158.

[16] Wu Q, Tan Z, Liu H, Gao L, Wu S, Luo J, Zhang W, Zhao T, Yu J, Xu X. Chemical characterization of Auricularia auricula polysaccharides and its pharmacological effect on heart antioxidant enzyme activities and left ventricular function in aged mice. International journal of biological macromolecules, 2010; 46: 284-288.

[17] YuJ, Sun R,Zhao Z,Wang Y. Auricularia polytricha polysaccharides induce cell cycle arrest and apoptosis in human lung cancer A549 cells. International Journal of Biological Macromolecules, 2014; 68: 67-71.

[18] Valverde ME, Hernández-Pérez T, Paredes-López, O. Edible mushrooms: improving human health and promoting quality life. International journal of microbiology, 2015.

[19] Elkhateeb, W. A., El-Hagrassi, A. M., Fayad, W., El-Manawaty, M. A. Cytotoxicity and hypoglycemic effect of the Japanese Jelly mushroom Auricularia auricula-judae. Chemistry Research Journal, 2018; 3: 123-133.

[20] Bandara A, Rapior S, Mortimer P, Kakumyan P, Hyde KD, Xu J. A review of the polysaccharide, protein and selected nutrient content of Auricularia, and their potential pharmacological value. Mycosphere, 2019; 10(1): 579-607 
[21] Kadnikova I, Costa R, Kalenik T, Guruleva O, Yanguo S. Chemical composition and nutritional value of the mushroom Auricularia auricula-judae. Journal of Food Nutrients Research, 2015; 3(8): 478-482.

[22] Roody WC. Mushrooms of West Virginia and the central Appalachians, University Press of Kentucky2015.

[23] De Roman M. The contribution of wild fungi to diet, income and health: a world review. in Progress in mycology, Springer. 2010; 327-348.

[24] Calonge FD. Flora Mycologica Iberica, vol. 3: Gasteromycetes, I. Lycoperdales, Nidulariales, Phallales, Sclerodermatales, Tulostomatales. Madrid/Berlin/Stuttgart, Real Jardín Botánico de Madrid/J. Cramer 1998.

[25] Leite A, Calonge FD, Baseia IG. Additional studies on Geastrum from northeastern Brazil 2007.

[26] Bates ST. Arizona members of the Geastraceae and Lycoperdaceae (Basidiomycota, Fungi), Arizona State University Tempe 2004.

[27] Sanjeev K, and Sharma Y. Systematics studies on Geastrum species from Jammu province. Journal of Plant Development Sciences2011; 3, 61-65.

[28] Sarac N, Alli H, Baygar T, Ugur, A. In vitro anticoagulant and antiinflammatory activities of Geastrum fimbriatum Fr., namely as Earthstar fungus. International Journal of Secondary Metabolite, 2019; 6(1): 19.

[29] Elo J, Estola E, Malmstrom N. Anticoagulants in fungi. in Annales medicinae experimentalis et biologiae Fenniae 1953.

[30] Ernst E. Herbal medicines: balancing benefits and risks. in Novartis Found Symp, Wiley Online Library 2007.

[31] Arora D. Mushrooms demystified. Ed. Ten Speed Press. Berkeley, EUA 1986.

[32] Wasser SP. Reishi or ling zhi (Ganoderma lucidum). Encyclopedia of dietary supplements2005; 1, 603622.

[33] Benzie IF, and Wachtel-Galor S. Herbal medicine: biomolecular and clinical aspects, CRC press 2011.

[34] Jong S, and Birmingham J. Medicinal benefits of the mushroom Ganoderma. in Advances in applied microbiology, Elsevier. 1992; 101-134.

[35] Lincoff G. The National Audubon Society Field Guide to Mushrooms, Knopf 1981.

[36] Veena S, and Pandey M. Paddy straw as a substrate for the cultivation of Lingzhi or Reishi medicinal mushroom, Ganoderma lucidum (W. Curt.: Fr.) P. Karst. in India. International journal of medicinal mushrooms $2011 ; 13$.

[37] Zhang L, and Wang S. Study on the binding and packing cultivation technology of the G. lucidum's artificial alternative compost. Agr Tech Serv2010; 27, 516-517.

[38] Matute RG, Figlas D, Devalis R, Delmastro S, Curvetto N. Sunflower seed hulls as a main nutrient source for cultivating Ganoderma lucidum. Micologia aplicada international 2002; 14, 19-24.

[39] Priya B, and Robinka K. Supplementation of nitrogen source in wheat straw for improving cellulolytic potential of Ganoderma lucidum. International Journal of Pharma and Bio Sciences 2014; 5.

[40] Ueitele I, Kadhila-Muanding N, Matundu N. Evaluating the production of Ganoderma mushroom on corn cobs. African Journal of Biotechnology2014; 13.

[41] Kües U, Nelson DR, Liu C, Yu G.-J, Zhang J, Li J, Wang X.-C, Sun H. Genome analysis of medicinal Ganoderma spp. with plant-pathogenic and saprotrophic life-styles. Phytochemistry2015; 114, 18-37.

[42] Hapuarachchi K, Elkhateeb W, Karunarathna S, Cheng C, Bandara A, Kakumyan P, Hyde K, Daba G, Wen T. Current status of global Ganoderma cultivation, products, industry and market. Mycosphere2018; 9, 1025-1052.

[43] Mau J.-L, Lin H.-C, Chen C.-C. Non-volatile components of several medicinal mushrooms. Food Research International2001; 34, 521-526.

[44] Boh B, Berovic M, Zhang J, Zhi-Bin L. Ganoderma lucidum and its pharmaceutically active compounds. Biotechnology annual review2007; 13, 265-301.

[45] Zhou X, Lin J, Yin Y, Zhao J, Sun X, Tang K. Ganodermataceae: natural products and their related pharmacological functions. The American journal of Chinese medicine 2007; 35, 559-574.

[46] Miyazaki T, and Nishijima M. Studies on fungal polysaccharides. XXVII. Structural examination of a water-soluble, antitumor polysaccharide of Ganoderma lucidum. Chemical and Pharmaceutical Bulletin1981; 29, 3611-3616.

[47] Hikino H, Konno C, Mirin Y, Hayashi T. Isolation and hypoglycemic activity of ganoderans A and B, glycans of Ganoderma lucidum fruit bodies. Planta medica1985; 51, 339-340. 
[48] Bao X, Liu C, Fang J, Li X. Structural and immunological studies of a major polysaccharide from spores of Ganoderma lucidum (Fr.) Karst. Carbohydrate research 2001; 332, 67-74.

[49] Chien CM, Cheng J.-L, Chang W.-T, Tien M.-H, Tsao C.-M, Chang Y.-H, Chang H.-Y, Hsieh J.-F, Wong C.-H, Chen S.-T. Polysaccharides of Ganoderma lucidum alter cell immunophenotypic expression and enhance CD56+ NK-cell cytotoxicity in cord blood. Bioorganic \& medicinal chemistry2004; 12, 56035609.

[50] Wu Y, and Wang D. A new class of natural glycopeptides with sugar moiety-dependent antioxidant activities derived from Ganoderma lucidum fruiting bodies. Journal of proteome research2008; 8, 436442.

[51] Mahato SB, and Sen S. Advances in triterpenoid research, 1990-1994. Phytochemistry1997; 44, 11851236.

[52] Chen DH, Shiou WY, Wang KC, Huang SY, Shie YT, Tsai CM, Shie JF, Chen, K. D. Chemotaxonomy of triterpenoid pattern of HPLC of Ganoderma lucidum and Ganoderma tsugae. Journal of the Chinese Chemical Society1999; 46, 47-51.

[53] Kubota T, Asaka Y, Miura I, Mori H. Structures of Ganoderic Acid A and B, Two New Lanostane Type Bitter Triterpenes from Ganoderma lucidum (FR.) KARST. Helvetica Chimica Acta1982; 65, 611-619.

[54] Budavari S. The Merck Index. elevan. New Jersey: Merck \& Co. Inc 1989.

[55] Chen T, Li K, He X, Zhu P, Xu J. Micro-morphology, chemical components and identification of logcultivated Ganoderma lucidum spore. in Proc'98 Nanjing Intl Symp Science \& Cultivation of Mushrooms 1998.

[56] Jun T, and Ke-yan F. Experimental and clinical studies on inhibitory effect of Ganoderma lucidum on platelet aggregation. Journal of Tongji Medical University1990; 10, 240-243.

[57] Choi H.-S, and Sa Y.-S. Fibrinolytic and antithrombotic protease from Ganoderma lucidum. Mycologia2000; 92, 545-552.

[58] Xie Y.-Z, Yang F, Tan W, Li X, Jiao C, Huang R, Yang BB. The anti-cancer components of Ganoderma lucidum possessescardiovascular protective effect by regulating circular RNA expression. Oncoscience2016; 3, 203.

[59] Wang GJ, Huang YJ, Chen DH, Lin YL.Ganoderma lucidum extract attenuates the proliferation of hepatic stellate cells by blocking the PDGF receptor. Phytotherapy Research: An International Journal Devoted to Pharmacological and Toxicological Evaluation of Natural Product Derivatives 2009; 23, 833-839.

[60] Ahmad MF. Ganoderma lucidum: Persuasive biologically active constituents and their health endorsement. Biomedicine \& Pharmacotherapy 2018; 107, 507-519.

Citation: Waill A. Elkhateeb, et.al., (2019). Anticoagulant Capacities of Some Medicinal Mushrooms. ARC Journal of Pharmaceutical Sciences (AJPS), 5(4), pp.1-9. DOI: http://dx.doi.org/10.20431/24551538.0504001

Copyright: (c) 2019 Authors. This is an open-access article distributed under the terms of the Creative Commons Attribution License, which permits unrestricted use, distribution, and reproduction in any medium, provided the original author and source are credited. 